\title{
Methylprednisolone inhibits the proliferation of endogenous neural stem cells in nonhuman primates with spinal cord injury
}

\author{
*Jichao Ye, MD, ${ }^{1}$ Yi Qin, MD, ${ }^{2}$ Yong Tang, MD, ${ }^{1}$ Mengjun Ma, MD, ${ }^{1}$ Peng Wang, PhD, ${ }^{1}$ \\ Lin Huang, MD, ${ }^{1}$ Rui Yang, MD, ${ }^{1}$ Keng Chen, MD, ${ }^{1}$ Chaopeng Chai, MD, ${ }^{1}$ Yanfeng Wu, MM, ${ }^{3}$ and \\ Huiyong Shen, MD'1 \\ ${ }^{1}$ Department of Orthopedics, Sun Yat-sen Memorial Hospital, Sun Yat-sen University; ${ }^{2}$ Department of Orthopedics, \\ Zhuhai People's Hospital; and 'Biotherapy Centre, Sun Yat-sen Memorial Hospital, Sun Yat-sen University, Guangzhou, \\ Guangdong, China
}

OBJECTIVE The aim of this work was to investigate the effects of methylprednisolone on the proliferation of endogenous neural stem cells (ENSCs) in nonhuman primates with spinal cord injury (SCl).

METHODS A total of 14 healthy cynomolgus monkeys (Macaca fascicularis) (4-5 years of age) were randomly divided into 3 groups: the control group $(n=6), S C l$ group $(n=6)$, and methylprednisolone therapy group $(n=2)$. Only laminectomy was performed in the control animals at T-10. SCl was induced in monkeys using Allen's weight-drop method $(50 \mathrm{~mm}$ $\times 50 \mathrm{~g}$ ) to injure the posterior portion of the spinal cord at T-10. In the methylprednisolone therapy group, monkeys were intravenously infused with methylprednisolone $(30 \mathrm{mg} / \mathrm{kg})$ immediately after SCl. All animals were intravenously infused with 5-bromo-2-deoxyuridine (BrdU) $(50 \mathrm{mg} / \mathrm{kg} / \mathrm{day})$ for 3 days prior to study end point. The small intestine was dissected for immunohistochemical examination. After 3, 7, and 14 days, the spinal cord segments of the control and SCl groups were dissected to prepare frozen and paraffin sections. The proliferation of ENSCs was evaluated using BrdU and nestin immunofluorescence staining.

RESULTS Histological examination showed that a larger number of mucosa epithelial cells in the small intestine of all groups were BrdU positive. Nestin-positive ependymal cells are increased around the central canal after SCl. After 3, 7 , and 14 days of $\mathrm{SCl}$, BrdU-positive ependymal cells in the $\mathrm{SCl}$ group were significantly increased compared with the control group, and the percentage of BrdU-positive cells in the left/right ventral horns and dorsal horn was significantly higher than that of the control group. Seven days after SCl, the percentages of both BrdU-positive ependymal cells around the central canal and BrdU- and nestin-double positive cells in the left/right ventral horns and dorsal horn were significantly lower in the methylprednisolone therapy group than in the $\mathrm{SCl}$ group.

CONCLUSIONS While ENSCs proliferate significantly after SCI in nonhuman primates, methylprednisolone can inhibit the proliferation of ependymal cells after SCl.

https://thejns.org/doi/abs/10.3171/2017.12.SPINE17669

KEYWORDS spinal cord injury; nonhuman primates; endogenous neural stem cells; methylprednisolone; proliferation

I $\mathrm{N}$ recent years, stem cell transplantation has been widely used for the treatment of CNS injury. Stem cells have the potential to cure many CNS diseases as they are not yet specialized and have the potential to become a variety of specialized cells in the human body. ${ }^{24}$ Neurons and glia could be successfully generated from stem cells such as embryonic stem cells (ESCs), mesenchymal stem cells (MSCs), neural stem cells (NSCs), neural stem/progenitor cells (NSPCs), and induced pluripotent stem cells (iPSCs). ${ }^{6,7,27,39,43}$ NSCs present attractive targets in stem cell transplantation therapy due to their self-replicating ability and multidirectional differentiation potential ${ }^{18}$ Many stud-

ABBREVIATIONS BrdU = 5-bromo-2-deoxyuridine; ENSC = endogenous neural stem cell; ESC = embryonic stem cell; $\mathrm{MP}=$ methylprednisolone; $\mathrm{NPC}=$ neural precursor cell; NSC = neural stem cell; PBS = phosphate-buffered saline; $\mathrm{SCl}=$ spinal cord injury.

SUBMITTED June 15, 2017. ACCEPTED December 12, 2017.

INCLUDE WHEN CITING Published online May 18, 2018; DOI: 10.3171/2017.12.SPINE17669.

* J.Y. and Y.Q. contributed equally to this work. 
ies have reported that NSC transplantation promoted the recovery of nerve function after spinal cord injury (SCI) in both rodent and nonhuman primate SCI models. For example, McDonald et al. transplanted neural differentiated mouse ESCs into rat spinal cords 9 days after traumatic injury. The authors observed that transplanted ESCs differentiated into astrocytes, oligodendrocytes, and neurons, thus promoting recovery in the injured rat spinal cords. ${ }^{26}$ In addition, it has been reported that transplanted NSCs can secrete various neurotrophic factors and cytokines to promote axonal regeneration and myelination. ${ }^{23,46} \mathrm{How}-$ ever, there are still a series of key problems in exogenous NSC transplantation for the treatment of SCI, including cell compatibility and rejection, incomplete differentiation of transplanted NSCs due to altered microenvironment in injured spinal cords, and abnormal pain. ${ }^{12}$ Therefore, experimental strategies designed to enhance the reactivation and mobilization of endogenous neural stem cells (ENSCs) have appeared and may lead to novel therapeutic approaches to treat CNS diseases. ${ }^{32}$ It is well established that ENSCs exist in the cerebral cortex, lateral ventricle, hippocampus, striatum, and central ependymal region of the spinal cord in both mammalian embryos and adult animals. ${ }^{21,31}$ ENSCs have the same biological characteristics as all NSCs, including the ability for self-renewal and differentiation into neurons and astrocytes.

Methylprednisolone (MP) is one of the steroids currently approved by the US Food and Drug Administration for the treatment of acute SCI in patients. ${ }^{1}$ It has been shown that MP inhibits the activation and proliferation of various inflammatory cell types in animal models of SCI by reducing the production of inflammatory cytokines/chemokines and free radicals, as well as inhibiting lipid peroxidation. ${ }^{7}$ It has also been shown that MP inhibits the proliferation and migration of ENSCs and oligodendrocytes after SCI. ${ }^{27}$ However, most of these studies were conducted in rats or mice, or other rodents, or with cells isolated from these animals. Due to the fact that there are significant differences in CNS, physiology, immune system, and molecular mechanisms of inflammation between rodents and primates, it is essential to investigate the effects of MP on SCI in nonhuman primate models.

In the present study, we first established the nonhuman primate SCI model in cynomolgus monkeys. Then, we evaluated the proliferation of ENSCs after SCI, and the effects of MP treatment on the proliferation of ENSCs in the spinal cords, to verify the effects of MP therapy on SCI in a nonhuman primate model.

\section{Methods \\ Ethics Statement}

All animal studies were approved by the Research Institute for Spinal Cord Injury at Sun Yat-sen University (Guangzhou, Guangdong, China) and were performed in accordance with the ethical standards outlined in the 1964 Declaration of Helsinki and its later amendments.

\section{Establishment of the SCI Model in Cynomolgus Monkeys}

A total of 14 healthy cynomolgus monkeys (Macaca fascicularis) (male/female ratio 1:1; age $4-5$ years; and weight 4.8-5.6 kg) were purchased from the Blue Island Biotechnology Co., Ltd. Animal breeding and surgery were conducted in the experimental base of Blue Island Biotechnology Co., Ltd. The animals were housed in a room maintained at $24^{\circ} \mathrm{C} \pm 4^{\circ} \mathrm{C}$ and a relative humidity of $50 \% \pm 10 \%$, with a 12-hour/12-hour light-dark cycle. Throughout the study, the animals were fed a commercial diet twice daily at 9:00 AM and 2:00 PM and were given drinking water ad libitum.

Eight cynomolgus monkeys were anesthetized by intraperitoneal injection of $10 \%$ pentobarbital $(300 \mathrm{mg} / \mathrm{kg})$. Ten minutes after induction of anesthesia, the animals were fixed on a board to remove back hair. After conventional iodine disinfection of the skin, thoracic laminectomy at the T-10 level was conducted through an incision in the back. The T-10 lamina was removed using microscissors to expose the dura. The T-10 spinal cord was injured using an NYU MASCIS impactor $(50 \mathrm{~mm} \times 50 \mathrm{~g})$. Signs of the successful establishment of the SCI model are as follows: spastic swing of the tail, retraction and fluttering of the hindlimbs and body, and subsequent spastic paralysis of the hindlimbs. After the surgery, the animals were placed in individual cages at $22^{\circ} \mathrm{C}$ and the body was warmed using a heating pad. Animals received intravenous injection of penicillin $(20,000 \mathrm{U} / \mathrm{kg})$ twice a day in the first 3 days after the surgery to prevent infections. Bladders were gently massaged, and an increased dose of antibiotics was used for animals with urethral hemorrhage.

The 8 cynomolgus monkeys with SCI were randomly divided into 2 groups: the SCI group $(n=6)$ and the MP group $(n=2)$. The 2 animals in the MP group received intravenous infusion of MP $(30 \mathrm{mg} / \mathrm{kg})$ immediately after SCI. Intravenous infusion of MP was completed within 30 minutes. Another 6 cynomolgus monkeys, which only received thoracic laminectomy at the T-10 level and vehicle infusion, were used as the controls. All animals received intravenous infusion of 5-bromo-2-deoxyuridine (BrdU) $(50 \mathrm{mg} / \mathrm{kg} /$ day) for 3 days prior to sacrifice. The experiments were conducted at two stages because there were a limited number of animals. First, the proliferation of ependymal cells in spinal cords of the SCI group were evaluated 3, 7, and 14 days after SCI to identify the time when ependymal cells exhibited the highest rate of proliferation. To evaluate the proliferation of ependymal cells in the MP group, the ependymal cells in spinal cords were dissected when ependymal cells were at the highest rate of proliferation.

\section{Histopathology}

After anesthesia was induced with intraperitoneal injection of $10 \%$ pentobarbital $(300 \mathrm{mg} / \mathrm{kg})$, the animals were perfused with saline $(500 \mathrm{ml})$ followed by $4 \%$ paraformaldehyde $(200 \mathrm{ml})$ via the heart. The injured spinal cord segment along with $3 \mathrm{~mm}$ of the upper and $3 \mathrm{~mm}$ of the lower sections was dissected and fixed in $4 \%$ paraformaldehyde $(20 \mathrm{ml})$ for 24 hours. Then, the spinal cord segments were transferred to $30 \%$ sucrose solution for incubation overnight at $4^{\circ} \mathrm{C}$. Paraffin-embedded tissues were transversely sliced in 5- $\mu \mathrm{m}$ thickness to prepare sections. Tissue sections were stained with $\mathrm{H} \& \mathrm{E}$ and examined under light microscopy (Nikon). The small intestine was also dissected for immunohistochemical staining assay. 



FIG. 1. The histopathology of spinal cords in control and $\mathrm{SCl}$ animals. Dense and normal spinal cord structures were observed in the control animals. The damage to the spinal cord of the $\mathrm{SCl}$ group was located on the dorsal side on the center of the spinal cord. $H \& E$, original magnification $\times 100$. Figure is available in color online only.

\section{Immunohistochemical Staining}

Paraffin sections were dried in an incubator at $58^{\circ} \mathrm{C}$ overnight. After conventional xylene dewaxing and gradient alcohol dehydration, the tissue sections were incubated in $3 \% \mathrm{H}_{2} \mathrm{O}_{2}$ at $37^{\circ} \mathrm{C}$ for 10 minutes and rinsed 3 times with phosphate-buffered saline (PBS) for 5 minutes. The tissues were denatured using $2 \mathrm{~mol} / \mathrm{L} \mathrm{HCl}$ at room temperature for 30 minutes, dried with filter paper, and neutralized in $0.1 \mathrm{~mol} / \mathrm{L}$ sodium borate $(\mathrm{pH} 8.5)$ for 10 minutes. After drying with filter paper, the tissue sections were washed 3 times with PBS for 10 minutes. Then, $0.5 \%$ Triton X-100 was used to penetrate cell membranes for 30 minutes. The tissue sections were blocked in goat serum at $37^{\circ} \mathrm{C}$ for 10 minutes, incubated in the primary antibody in dark at $4^{\circ} \mathrm{C}$ overnight, and washed 3 times with PBS for 5 minutes. Then, the tissue sections were incubated with biotinylated secondary antibody at $37^{\circ} \mathrm{C}$ for 30 minutes and washed 3 times with PBS for 5 minutes. After washing with distilled water, the tissue sections were stained with $\mathrm{H} \& \mathrm{E}$, dehydrated, dried, and sealed. The tissues were examined under a microscope and photographed. The proliferation of BrdU-positive cells was evaluated under a microscope (Nikon; magnification $\times 100$ ) every fifth slice.

\section{Immunofluorescence Staining}

The tissue sections were fixed in cold acetone for 20 minutes, washed 3 times with PBS for 5 minutes, and treated with $3 \%$ hydrogen peroxide. The tissue sections were blocked in goat serum at $37^{\circ} \mathrm{C}$ for 30 minutes, incubated in $50 \mu \mathrm{l}$ of the primary antibody nestin (1:200) in dark at $4^{\circ} \mathrm{C}$ overnight, and washed 3 times with PBS for 5 minutes. PBS was used to replace the first antibody for a negative control. The tissue sections were incubated with goat anti-mouse IgG-FITC $(1: 100)$ at $37^{\circ} \mathrm{C}$ for 30 minutes and washed 3 times with PBS for 5 minutes. The tissue samples were examined under a microscope (magnification $\times 400)$ and photographed. Nestin-positive cells were counted on five slides. Image-Pro Plus 6.0 (Media Cyber- netics) was used to determine the integral optical density values of nestin in ependymal cells around the central canal $(\mathrm{n}=2,5$ slides/animal).

\section{Statistical Analyses}

Statistical analyses were conducted using SPSS version 19.0 statistical software (IBM Corp.). All data are expressed as the mean $\pm \mathrm{SD}$. The one-way ANOVA test followed by a Tukey-Kramer multiple comparisons posttest was used to analyze differences among the 3 groups, and differences between 2 groups were compared using an independent samples t-test. A p $<0.05$ was considered statistically significant.

\section{Results}

\section{Histopathological Changes After SCl}

The histopathological findings of spinal cord specimens from control and SCI animals were shown in Fig. 1. Dense and normal spinal cord tissue was observed in the control animals (Fig. 1 left). The damage to the spinal cord in the SCI group was located on the dorsal side on the center of the spinal cord. The unaffected white matter was confined to the lateral and ventral side. The spinal cord tissue was slightly damaged, with structural destruction and necrotic cysts (Fig. 1 right).

\section{BrdU-Positive Mucosal Epithelial Cells in the Small Intestine}

The small intestine tissues of SCI animals were dissected 3 days after intravenous injection of BrdU $(50 \mathrm{mg} / \mathrm{kg})$. Most (> 80\%) of the mucosal epithelial cells in the small intestine were BrdU positive, with brown nuclei staining (Fig. 2).

\section{Nestin-Positive Ependymal Cells in Spinal Cords}

The spinal cords of the control and SCI animals were dissected for nestin immunofluorescence staining. As shown in Fig. 3, nestin-positive ependymal cells around the 
J. Ye et al.

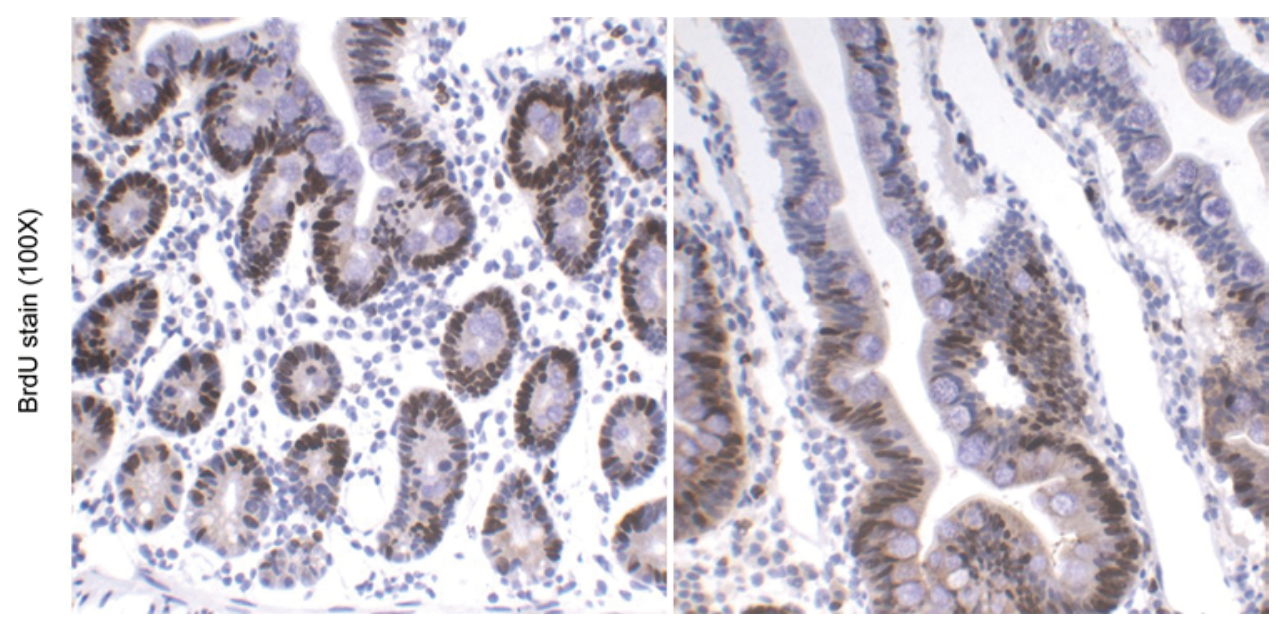

FIG. 2. BrdU immunohistochemical staining of small intestinal mucosal epithelia of $\mathrm{SCl}$ animals. Most (> $80 \%)$ of the mucosal epithelial cells in the small intestine were BrdU positive with brown nuclei staining. Original magnification $\times 100$. Figure is available in color online only.

central canal were observed under a light microscope. Ependymal cells in both control and SCI animals are ENSCs or neural precursor cells (NPCs). However, ependymal cells in the SCI animals exhibited stronger nestin staining than did ependymal cells in the control animals. The integral optical density values of the SCI animals were 32,328 $\pm 2291.3,40,812 \pm 1428.4$, and 34,736 $\pm 2128.53,7$, and 14 days after SCI, respectively, and these were significantly higher than that $(24,091 \pm 2240.2)$ seen in normal control animals $(\mathrm{p}<0.05)$.

\section{BrdU-Positive Ependymal Cells of SCI Animals}

BrdU staining was confined to the nucleus of ependymal cells. Scattered BrdU-positive ependymal cells were observed around the central canal of the spinal cord in the control animals. More BrdU-positive ependymal cells were observed around the central canal of the spinal cords in the SCI animals 3, 7, and 14 days after SCI (Fig. 4). There were significantly higher numbers of BrdU-positive ependymal cells around the central canal on days $3(11.5 \pm$ 6.4), $7(16.3 \pm 8.4)$, and $14(9.4 \pm 5.4)$ after SCI than were seen $(3.2 \pm 1.2)$ in the control animals.

\section{Nestin/BrdU-Positive Cells in the Ventral and Dorsal Horns of Spinal Cord Gray Matter}

The numbers of nestin-positive cells in the right ventral $(28.5 \pm 5.8,29.7 \pm 10.3$, and $20.9 \pm 10.1)$ and dorsal $(45.9$ $\pm 20.9,51.5 \pm 10.3$, and $48.6 \pm 7.2$ ) horns of the SCI group on the 3rd, 7th, and 14th days after SCI were significantly higher than were seen in the ventral $(15.5 \pm 7.3)$ and dorsal
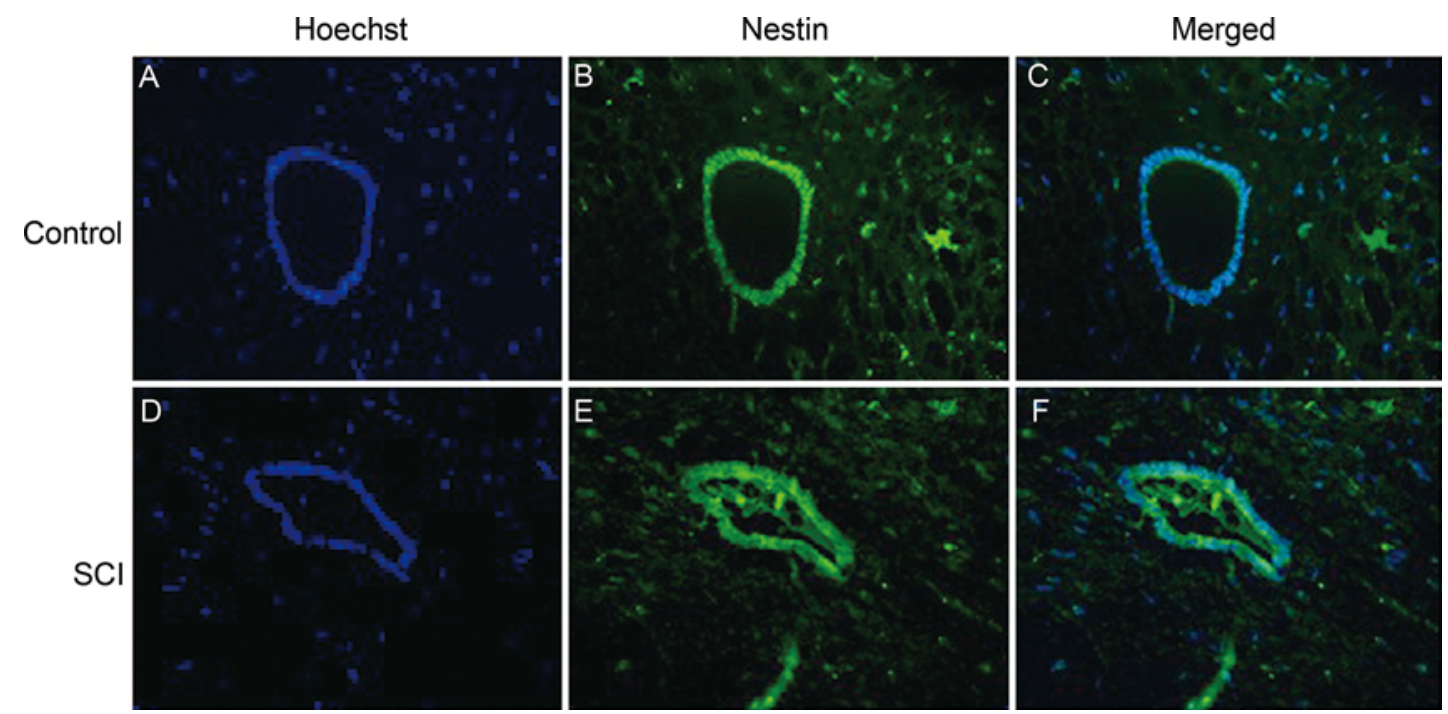

FIG. 3. Hoechst staining and nestin immunofluorescent staining of ependymal cells in control (A-C) and SCl (D-F) animals. Nestin-positive ependymal cells around the central canal were observed under a light microscope. Ependymal cells in both the control and SCl animals are ENSCs or NPCs. However, ependymal cells in the SCl animals exhibited stronger nestin staining than those of the control animals. Original magnification $\times 400$. Figure is available in color online only. 

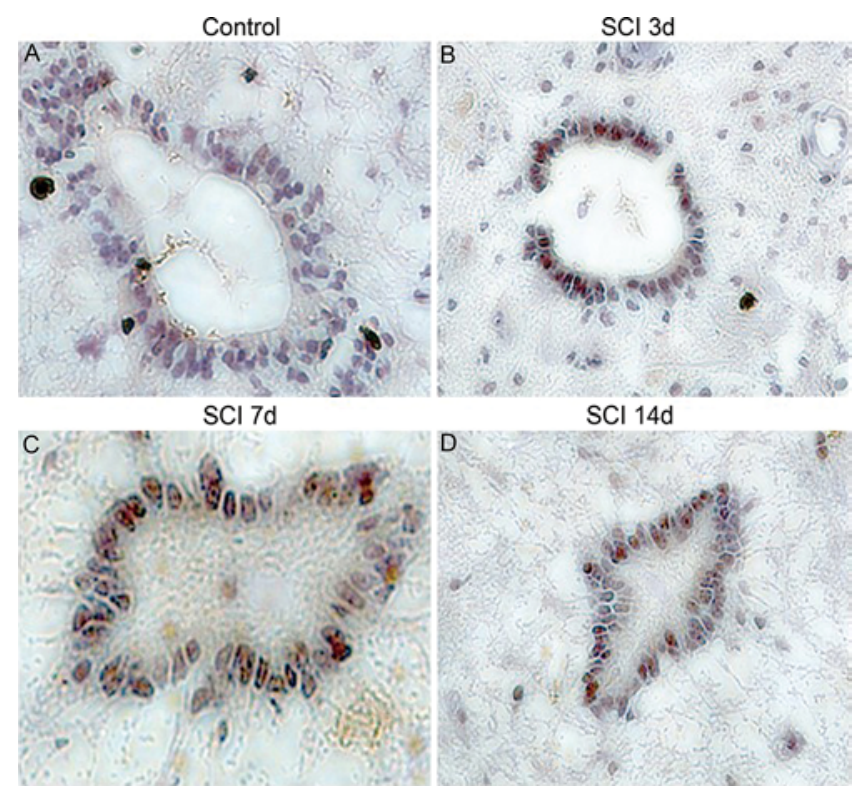

FIG. 4. BrdU immunohistochemical staining of ependymal cells in control animals (A) and SCl animals on days 3 (B), 7 (C), and 14 (D). This staining is confined to the nucleus of ependymal cells. Scattered BrdU-positive ependymal cells were observed around the central canal of the spinal cord of the control animals. More BrdU-positive ependymal cells were observed around the central canal of the spinal cord of the $\mathrm{SCl}$ animals on days 3,7 , and 14 after SCl. Original magnification $\times 400$. Figure is available in color online only.
TABLE 1. The number of nestin-positive cells in the gray matter of ventral and dorsal horns in control and $\mathrm{SCl}$ group monkeys

\begin{tabular}{lcccc}
\hline & & \multicolumn{3}{c}{ SCl Group } \\
\cline { 2 - 5 } Gray Matter & Control Group & Day 3 & Day 7 & Day 14 \\
\hline Ventral horn & $15.5 \pm 7.3$ & $28.5 \pm 5.8^{*}$ & $29.7 \pm 10.3^{*}$ & $20.9 \pm 10.1$ \\
\hline Dorsal horn & $34.6 \pm 11.5$ & $45.9 \pm 20.9$ & $51.5 \pm 10.3^{*}$ & $48.6 \pm 7.2^{*}$
\end{tabular}

* $p<0.05$ compared with control group (ANOVA followed by a Tukey-Kramer multiple comparisons post-test).

(34.6 \pm 11.5 ) horns of control animals (Fig. 5 and Table 1). Similarly, the numbers of BrdU-positive cells in the ventral $(31.5 \pm 9.82,29.3 \pm 12.65$, and $26.4 \pm 8.08)$ and dorsal $(55.9 \pm 15.9,61.5 \pm 9.6$, and $53.6 \pm 15.2)$ horns of the SCI group on the 3rd, 7th, and 14th days after SCI were also significantly higher than the number in the ventral (19.5 \pm 8.1) and dorsal (41.5 \pm 13.5 ) horns of control animals (Fig. 6 and Table 2).

\section{Nestin/BrdU-Positive Cells in Ventral and Dorsal Horns in $\mathrm{SCl}$ and MP Groups}

To evaluate the proliferation of ependymal cells in the MP group, the ependymal cells in spinal cords were dissected when ependymal cells had the highest rate of proliferation. Based on the results mentioned above, we compared nestin/BrdU-double positive cells between the SCI and MP groups on the 7th day after SCI. Our data suggested MP infusion significantly reduced the number of nestin/BrdU-positive cells in the ventral and dorsal horns (Fig. 7).



FIG. 5. Nestin-positive cells in the ventral and dorsal horns of spinal cord gray matter. The number of nestin-positive cells in the right ventral and dorsal horns of the SCl group (C and D) on day 7 after SCl was significantly higher than that in the ventral and dorsal horns of control animals (A and B). Original magnification $\times 100$. Figure is available in color online only. 


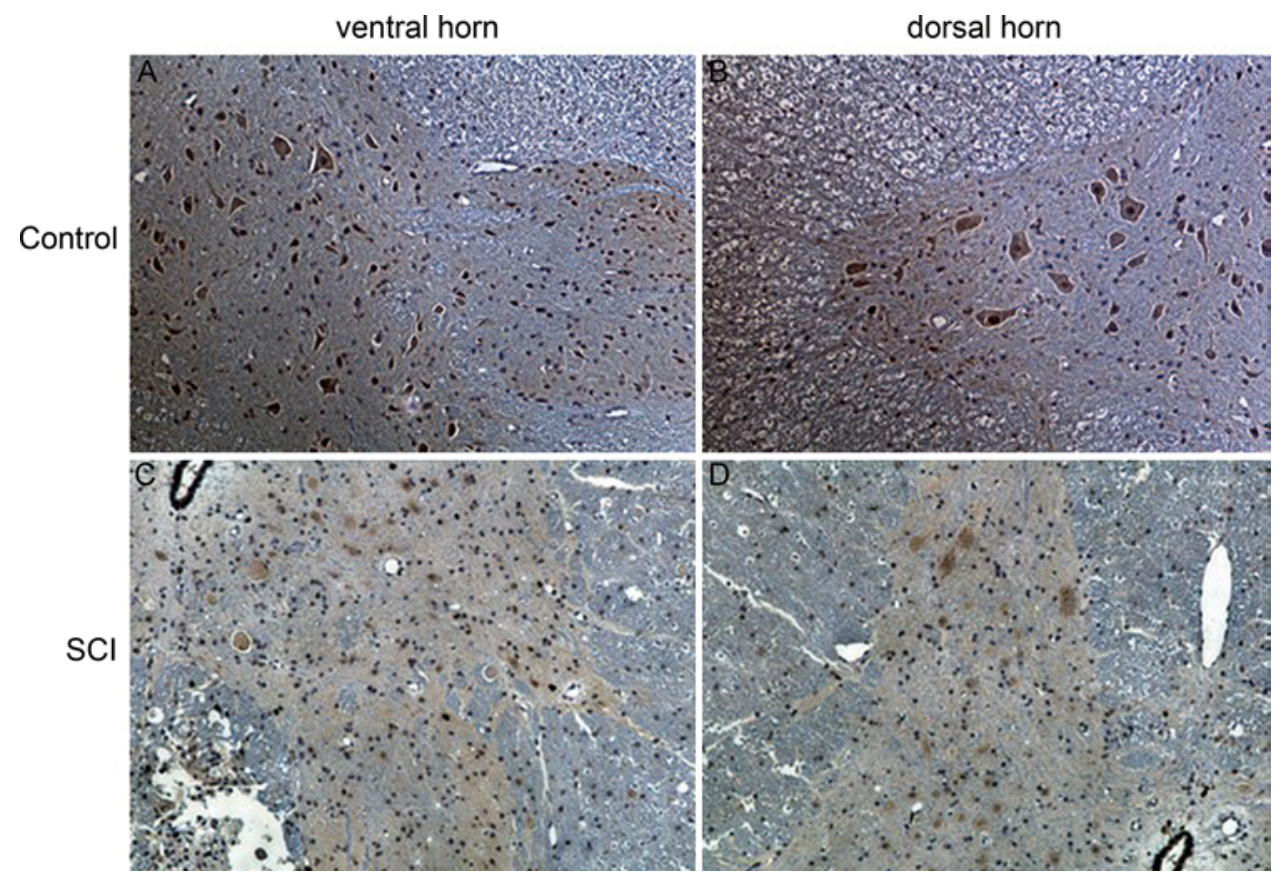

FIG. 6. BrdU-positive cells in the ventral and dorsal horns of spinal cord gray matter. The number of BrdU-positive cells in the right ventral and dorsal horns of the $\mathrm{SCl}$ group (C and $\mathbf{D}$ ) on day 7 after $\mathrm{SCl}$ was significantly higher than that in the ventral and dorsal horns of control animals (A and B). Original magnification $\times 100$. Figure is available in color online only.

\section{Discussion}

Spinal cord injury poses big challenges for public health because of its high incidence and high morbidity rate, and there are no satisfactory treatments available to date. ${ }^{17}$ Various approaches using stem cell transplantation have been attempted in the treatment of SCI. The role of ENSCs in the repair of CNS injury has been extensively studied in recent years. ${ }^{9,45}$ It is well established that SCI is accompanied by significant cell apoptosis and altered gene transcription. ${ }^{4}$ In higher vertebrates, such as monkeys and humans, axonal regeneration is very limited, and SCI usually results in permanent paralysis below the lesion. In contrast, lower vertebrates, such as mice and rats, display robust axonal regeneration and recovery of function within a few weeks. ${ }^{25}$ There are several reasons for this phenomenon: 1) the regenerative capability of neurons formed by NSCs is rather limited;2 2) several factors are produced by SCI that inhibit the growth of neurons; ${ }^{22} 3$ ) following SCI, many glial cell types are recruited to the lesion sites, forming the glial scar, which is an inhibitory component of axon growth. ${ }^{34}$ Unfortunately, no effective therapy has been introduced for treating SCI in higher primates. A recent study has demonstrated that rhesus monkey NSCs, as a subpopulation of stem cells present in the brain subventricular zone, can survive, differentiate to neurons, and promote functional recovery after SCI; ${ }^{29}$ another study has suggested that NSC-derived neurons may be efficient in the functional recovery through remyelination of axons and that they compensate for dead neurons. ${ }^{11}$ These findings show that NSCs exhibit the multipluripotent characteristic of differentiating into neurons and glial cells and that transplantation of NSCs into an injured spinal cord may provide a new therapeutic approach to treating SCI.
In the present study, we established an SCI model in cynomolgus monkeys to study the effects of MP on the proliferation of ENSCs in SCI. We counted the numbers of nestin-positive ependymal cells around the central canal in both the control and SCI groups. We observed that nestinpositive ependymal cells around the central canal in the SCI group exhibited significantly stronger nestin staining. Ependymal cells, which are original neuroepithelial cells including NPCs/NSCs, are columnar epithelia distributed in the ventricle and the central lumen of the spinal cord. ${ }^{3}$ In adult mammals, ependymal cells of the spinal cord have a limited capacity for proliferation. ${ }^{13}$ It has been shown that SCI induces ependymal cell proliferation, ${ }^{44}$ and proliferative ependymal cells exhibit characteristics of NPCs/ NSCs in SCI..$^{37,42}$ In adult rodents with SCI, elevated proliferation of ependymal cells has been observed; the cells can migrate to surrounding tissues and differentiate into astrocytes. ${ }^{16}$ These data indicate that NSCs in the central ventricle of the spinal cord play essential roles in SCI recovery. We also observed more BrdU-positive ependymal cells in the SCI group on the 3rd, 7th, and 14th days after $\mathrm{SCI}$ than we did in the control group. In addition, BrdU/ nestin-double positive cells in the right ventral and dorsal horns in the SCI group increased on the 3rd, 7th, and 14th days after SCI, a finding consistent with previous studies conducted in rodent SCI models..$^{8,35}$ Therefore, regarding ependymal cells, including NPCs or NSCs, our results confirm that the proliferation of ependymal cells was increased after SCI in the nonhuman primate model.

One study reported that SCI induced proliferation of ENSCs in adult mice and that the isolated ENSCs formed typical neurospheres and differentiated into neurons, oligodendrocytes, and astrocytes. ${ }^{38}$ However, most NSCs differentiate into astrocytes after SCI, which are not use- 
TABLE 2. The number of BrdU-positive cells in the gray matter of ventral and dorsal horns in control and $\mathrm{SCl}$ group monkeys

\begin{tabular}{lcccc}
\hline \multirow{2}{*}{ Gray Matter } & Control & \multicolumn{3}{c}{ SCl Group } \\
\cline { 3 - 5 } & Group & Day 3 & Day 7 & Day 14 \\
\hline Ventral horn & $19.5 \pm 8.1$ & $31.5 \pm 9.8^{*}$ & $29.3 \pm 12.7^{*}$ & $26.4 \pm 8.1^{*}$ \\
\hline Dorsal horn & $41.5 \pm 13.5$ & $55.9 \pm 15.9^{*}$ & $61.5 \pm 9.6^{*}$ & $53.6 \pm 15.2^{*}$
\end{tabular}

* $p<0.05$ compared with control group (ANOVA followed by a Tukey-Kramer multiple comparisons post-test).

ful for axillary myelination, and may lead to nerve scars, thus preventing the reconstruction of nerve bundles. ${ }^{15}$ Neurons in the adult mammalian CNS do not spontaneously regenerate axons after SCI due to CNS myelin and other inhibitory mechanisms..$^{10}$ Neurons are involved in the formation of synapses and the delivery of neurotransmitters, and they display neuroprotective effects following SCI ${ }^{19,41}$ however, the effects of astrocytes on the nervous system are more complex. On the one hand, they secrete neurotrophic and antiinflammatory factors to promote the survival of neurons; on the other hand, they also secrete some proinflammatory factors to accelerate the apoptosis of neurons. ${ }^{40}$ Piechota et al. reported that glial cells might be the primary targets of the transcriptional action of steroids in the CNS, ${ }^{33}$ and recent findings suggest that endogenous neurosteroids such as allopregnanolone can protect neurons from insults such as stroke and cerebral trauma. ${ }^{5,14}$ However, the effects of steroids on NSC differentiation are incompletely understood. Therefore, understanding the molecular mechanisms underlying ENSC proliferation and differentiation after steroid treatment is important for the management of SCI.

MP can inhibit the activation and proliferation of various inflammatory cell types, thereby reducing the production of inflammatory factors and free radicals, which are necessary to maintain a balanced microenvironment for axonal growth and regeneration..$^{28}$ In our study, we evaluated the effects of MP on the proliferation of ependymal cells on the 7th day after SCI when BrdU-positive cells reached their highest level. We found fewer nestin/BrdUpositive ependymal cells in the ventral and dorsal horns of the spinal cords on the 7th day after SCI in the MP group compared with the SCI group. Yu et al. found that glucocorticoid induced the apoptosis of ENSCs in the dentate gyrus and immature neurons in neonatal mice, affecting the development of the dentate gyrus in neonatal mice. ${ }^{47}$ High-dose MP treatment in a mouse model of SCI has been shown to inhibit the proliferation of ENSCs and oligodendrocyte progenitor cells in spinal cords. ${ }^{36}$ As the main structure of myelin in the spinal cord, oligodendrocytes can induce remyelination of unmyelinated nerve axons. After SCI, NSCs preferentially differentiate into astrocytes, contributing to glial scarring, which is the most important inhibitory factor for neuroregeneration after SCI. ${ }^{20}$ The change in the local microenvironment produced by SCI may be the main cause of this phenomenon, in which a large number of inflammatory factors was secreted, thereby promoting the differentiation of astrocytes and induction of NSCs to differentiate into glial cells. ${ }^{30}$

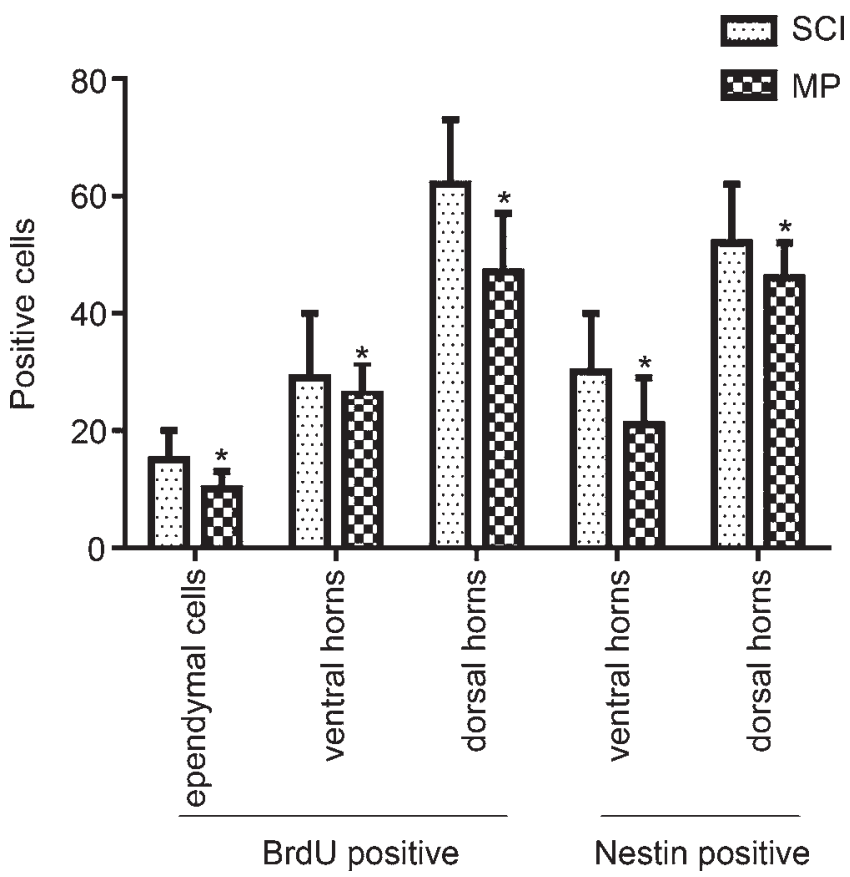

FIG. 7. Nestin/BrdU-double positive ependymal cells in ventral and dorsal horns of spinal cord in SCl and MP animals. The number of nestin/BrdU-double positive ependymal cells was significantly decreased in the MP group compared with the $\mathrm{SCl}$ group. ${ }^{*} p<0.05$ versus $\mathrm{SCl}$ group.

\section{Limitations}

The major limitation of our study is the relatively small sample size, especially in the MP treatment group. Therefore, studies based on a larger sample size of the SCI model in nonhuman primates should be conducted in the future. In addition, labeling ENSCs in vivo in nonhuman primate SCI models and investigating the proliferation, migration, and differentiation of ENSCs in vivo will be useful for understanding the molecular mechanism underlying the inhibitory effects of MP on ENSC proliferation.

\section{Conclusions}

Based on current and previous findings, we speculate that MP inhibits the proliferation of ENSCs and oligodendrocyte progenitor cells. We demonstrated increased ependymal cell proliferation in a nonhuman primate SCI model and observed that MP inhibited the proliferation of ependymal cells. Although NSC transplantation has been widely used to explore strategies for functional recovery after SCI in rodent models, there is still a ways to go before the clinical application, for several reasons, such as the difficulty of the separation and enrichment of NSCs, expensive surgical costs, and potential tumorigenicity after NSC transplantation.

\section{Acknowledgments}

This study was supported by National Natural Science Foundation of China (no. U1301223); Science and Technology Planning Project of Guangzhou, China (no. 201707010273); Science and Technology Planning Project of Guangdong Province, China (nos. 2016A020225001 and 2017A020213024); Guangdong Provincial Medical Science and Technology Research Fund (no. A2016233); 
and Established Project of Guangdong Provincial Bureau of Traditional Chinese Medicine (no. 20161233).

\section{References}

1. Breslin K, Agrawal D: The use of methylprednisolone in acute spinal cord injury: a review of the evidence, controversies, and recommendations. Pediatr Emerg Care 28:12381248,2012

2. Caroni P: Neuro-regeneration: plasticity for repair and adaptation. Essays Biochem 33:53-64, 1998

3. Del Bigio MR: The ependyma: a protective barrier between brain and cerebrospinal fluid. Glia 14:1-13, 1995

4. Di Giovanni S, Knoblach SM, Brandoli C, Aden SA, Hoffman EP, Faden AI: Gene profiling in spinal cord injury shows role of cell cycle in neuronal death. Ann Neurol 53:454-468, 2003

5. Djebaili M, Guo Q, Pettus EH, Hoffman SW, Stein DG: The neurosteroids progesterone and allopregnanolone reduce cell death, gliosis, and functional deficits after traumatic brain injury in rats. J Neurotrauma 22:106-118, 2005

6. Enzmann GU, Benton RL, Talbott JF, Cao Q, Whittemore SR: Functional considerations of stem cell transplantation therapy for spinal cord repair. J Neurotrauma 23:479-495, 2006

7. Fehlings MG, Vawda R: Cellular treatments for spinal cord injury: the time is right for clinical trials. Neurotherapeutics 8:704-720, 2011

8. Fujimoto Y, Abematsu M, Falk A, Tsujimura K, Sanosaka T, Juliandi B, et al: Treatment of a mouse model of spinal cord injury by transplantation of human induced pluripotent stem cell-derived long-term self-renewing neuroepithelial-like stem cells. Stem Cells 30:1163-1173, 2012

9. Garbossa D, Boido M, Fontanella M, Fronda C, Ducati A, Vercelli A: Recent therapeutic strategies for spinal cord injury treatment: possible role of stem cells. Neurosurg Rev 35:293-311, 2012

10. Gu H, Yu SP, Gutekunst CA, Gross RE, Wei L: Inhibition of the Rho signaling pathway improves neurite outgrowth and neuronal differentiation of mouse neural stem cells. Int J Physiol Pathophysiol Pharmacol 5:11-20, 2013

11. Hatami M, Mehrjardi NZ, Kiani S, Hemmesi K, Azizi H, Shahverdi A, et al: Human embryonic stem cell-derived neural precursor transplants in collagen scaffolds promote recovery in injured rat spinal cord. Cytotherapy 11:618-630, 2009

12. Hofstetter CP, Holmström NA, Lilja JA, Schweinhardt P, Hao J, Spenger C, et al: Allodynia limits the usefulness of intraspinal neural stem cell grafts; directed differentiation improves outcome. Nat Neurosci 8:346-353, 2005

13. Horner PJ, Power AE, Kempermann G, Kuhn HG, Palmer TD, Winkler J, et al: Proliferation and differentiation of progenitor cells throughout the intact adult rat spinal cord. $\mathbf{J}$ Neurosci 20:2218-2228, 2000

14. Ishikawa M, Yoshitomi T, Zorumski CF, Izumi Y: Neurosteroids are endogenous neuroprotectants in an ex vivo glaucoma model. Invest Ophthalmol Vis Sci 55:8531-8541, 2014

15. Johansson CB, Momma S, Clarke DL, Risling M, Lendahl U, Frisén J: Identification of a neural stem cell in the adult mammalian central nervous system. Cell 96:25-34, 1999

16. Kalyani A, Hobson K, Rao MS: Neuroepithelial stem cells from the embryonic spinal cord: isolation, characterization, and clonal analysis. Dev Biol 186:202-223, 1997

17. Kehn M, Kroll T: Reporting trends of spinal cord injury research representation: a media content analysis. Disabil Health J 4:121-128, 2011

18. Kennea NL, Mehmet H: Neural stem cells. J Pathol 197:536-550, 2002
19. Kim YJ, Park HJ, Lee G, Bang OY, Ahn YH, Joe E, et al: Neuroprotective effects of human mesenchymal stem cells on dopaminergic neurons through anti-inflammatory action. Glia 57:13-23, 2009

20. Leal-Filho MB: Spinal cord injury: from inflammation to glial scar. Surg Neurol Int 2:112, 2011

21. Liu Y, Tan B, Wang L, Long Z, Li Y, Liao W, et al: Endogenous neural stem cells in central canal of adult rats acquired limited ability to differentiate into neurons following mild spinal cord injury. Int J Clin Exp Pathol 8:3835-3842, 2015

22. Logan A, Ahmed Z, Baird A, Gonzalez AM, Berry M: Neurotrophic factor synergy is required for neuronal survival and disinhibited axon regeneration after CNS injury. Brain 129:490-502, 2006

23. Lu P, Jones LL, Snyder EY, Tuszynski MH: Neural stem cells constitutively secrete neurotrophic factors and promote extensive host axonal growth after spinal cord injury. Exp Neurol 181:115-129, 2003

24. Magnus T, Rao MS: Neural stem cells in inflammatory CNS diseases: mechanisms and therapy. J Cell Mol Med 9:303319, 2005

25. McClellan AD: Functional axonal regeneration following spinal cord injury. Brain Res Bull 50:403-404, 1999

26. McDonald JW, Liu XZ, Qu Y, Liu S, Mickey SK, Turetsky D, et al: Transplanted embryonic stem cells survive, differentiate and promote recovery in injured rat spinal cord. Nat Med 5:1410-1412, 1999

27. Muheremu A, Peng J, Ao Q: Stem cell based therapies for spinal cord injury. Tissue Cell 48:328-333, 2016

28. Nash HH, Borke RC, Anders JJ: Ensheathing cells and methylprednisolone promote axonal regeneration and functional recovery in the lesioned adult rat spinal cord. J Neurosci 22:7111-7120, 2002

29. Nemati SN, Jabbari R, Hajinasrollah M, Zare Mehrjerdi N, Azizi H, Hemmesi K, et al: Transplantation of adult monkey neural stem cells into a contusion spinal cord injury model in rhesus macaque monkeys. Cell J 16:117-130, 2014

30. Nishimura S, Yasuda A, Iwai H, Takano M, Kobayashi Y, Nori S, et al: Time-dependent changes in the microenvironment of injured spinal cord affects the therapeutic potential of neural stem cell transplantation for spinal cord injury. Mol Brain 6:3, 2013

31. Panayiotou E, Malas S: Adult spinal cord ependymal layer: a promising pool of quiescent stem cells to treat spinal cord injury. Front Physiol 4:340, 2013

32. Picard-Riera N, Nait-Oumesmar B, Baron-Van Evercooren A: Endogenous adult neural stem cells: limits and potential to repair the injured central nervous system. J Neurosci Res 76:223-231, 2004

33. Piechota M, Korostynski M, Golda S, Ficek J, Jantas D, Barbara Z, et al: Transcriptional signatures of steroid hormones in the striatal neurons and astrocytes. BMC Neurosci 18:37, 2017

34. Rhodes KE, Moon LD, Fawcett JW: Inhibiting cell proliferation during formation of the glial scar: effects on axon regeneration in the CNS. Neuroscience 120:41-56, 2003

35. Ronaghi M, Erceg S, Moreno-Manzano V, Stojkovic M: Challenges of stem cell therapy for spinal cord injury: human embryonic stem cells, endogenous neural stem cells, or induced pluripotent stem cells? Stem Cells 28:93-99, 2010

36. Schröter A, Lustenberger RM, Obermair FJ, Thallmair M: High-dose corticosteroids after spinal cord injury reduce neural progenitor cell proliferation. Neuroscience 161:753763, 2009

37. Shibuya S, Miyamoto O, Auer RN, Itano T, Mori S, Norimatsu H: Embryonic intermediate filament, nestin, expression following traumatic spinal cord injury in adult rats. Neuroscience 114:905-916, 2002

38. Shihabuddin LS, Horner PJ, Ray J, Gage FH: Adult spinal 
cord stem cells generate neurons after transplantation in the adult dentate gyrus. J Neurosci 20:8727-8735, 2000

39. Silver JR: A systematic review of the therapeutic interventions for heterotopic ossification after spinal cord injury. Spinal Cord 49:482, 484, 2011 (Letter)

40. Sofroniew MV, Vinters HV: Astrocytes: biology and pathology. Acta Neuropathol 119:7-35, 2010

41. Sulzer D, Joyce MP, Lin L, Geldwert D, Haber SN, Hattori $\mathrm{T}$, et al: Dopamine neurons make glutamatergic synapses in vitro. J Neurosci 18:4588-4602, 1998

42. Takahashi M, Arai Y, Kurosawa H, Sueyoshi N, Shirai S: Ependymal cell reactions in spinal cord segments after compression injury in adult rat. J Neuropathol Exp Neurol 62:185-194, 2003

43. Tetzlaff W, Okon EB, Karimi-Abdolrezaee S, Hill CE, Sparling JS, Plemel JR, et al: A systematic review of cellular transplantation therapies for spinal cord injury. J Neurotrauma 28:1611-1682, 2011

44. Wallace MC, Tator $\mathrm{CH}$, Lewis AJ: Chronic regenerative changes in the spinal cord after cord compression injury in rats. Surg Neurol 27:209-219, 1987

45. Wang G, Ao Q, Gong K, Zuo H, Gong Y, Zhang X: Synergistic effect of neural stem cells and olfactory ensheathing cells on repair of adult rat spinal cord injury. Cell Transplant 19:1325-1337, 2010

46. Yan J, Welsh AM, Bora SH, Snyder EY, Koliatsos VE: Differentiation and tropic/trophic effects of exogenous neural precursors in the adult spinal cord. J Comp Neurol 480:101114,2004

47. Yu S, Patchev AV, Wu Y, Lu J, Holsboer F, Zhang JZ, et al: Depletion of the neural precursor cell pool by glucocorticoids. Ann Neurol 67:21-30, 2010

\section{Disclosures}

The authors report no conflict of interest concerning the materials or methods used in this study or the findings specified in this paper.

\section{Author Contributions}

Conception and design: Shen, Ye. Acquisition of data: Ye, Qin, $\mathrm{Ma}$, Chen. Analysis and interpretation of data: Wang. Drafting the article: Shen, Ye, Qin, Wang. Critically revising the article: Shen, Tang, Ma, Huang, Yang, Wu. Reviewed submitted version of manuscript: Shen, Qin, Tang, Huang, Yang, Chen. Approved the final version of the manuscript on behalf of all authors: Shen. Statistical analysis: Shen, Ma, Wang, Chen, Chai, Wu. Administrative/technical/material support: Tang, Wang, Huang, Yang, Chai. Study supervision: Qin, Tang, Ma, Huang, Yang, Chai, Wu.

\section{Correspondence}

Huiyong Shen: Sun Yat-sen Memorial Hospital, Sun Yat-sen University, Guangzhou, China. shyshenhuiyong@163.com. 